Dicle Üniversitesi Veteriner Fakültesi Dergisi
https://dergipark.org.tr/tr/pub/duvetfd
Araştırma Makalesi/Research Article
Dicle Üniv Vet Fak Derg 2021;14(2):104-106
DOI: 10.47027/duvetfd.982490

\title{
Anadolu Mandalarında Vajinal Bakteriyel ve Fungal Flora
}

\author{
Nurdan KARACAN SEVER ${ }^{1, a, 凶}$, Mehmet Ferit ÖZMEN²,b \\ ${ }^{1}$ Dicle Üniversitesi, Veteriner Fakültesi, Mikrobiyoloji Anabilim Dalı, Diyarbakır, TÜRKiYE \\ 2Dicle Üniversitesi, Veteriner Fakültesi, Dölerme ve Suni Tohumlama Anabilim Dalı, Diyarbakır, TÜRKiYE
}

aORCID: 0000-0002-0618-5822; bORCID: 0000-0002-5531-220X

\begin{tabular}{ccc}
\hline Geliş Tarihi/Received & Kabul Tarihi/Accepted & Yayın Tarihi/Published \\
13.08 .2021 & 24.09 .2021 & 31.12 .2021 \\
\hline
\end{tabular}

Öz

Vajinal mikrobiyal flora, genital sistemi infeksiyonlara karşı korumada önemli bir rol oynamaktadır. Bu çalışmada Anadolu mandalarının vajinal bakteriyel (aerobik veya fakültatif anaerobik) ve fungal florası araştırıldı. Dicle Üniversitesi Veteriner Fakültesi Eğitim Araştırma ve Uygulama Çiftliği'nde daha önce çiftleşmemiş ve klinik olarak sağlıklı 14 Anadolu mandasından vajinal sıvap örnekleri toplandı. Bakteriyel ve fungal etkenlerin izolasyon ve identifikasyonları standart yöntemler kullanılarak gerçekleştirildi. Staphylococcus spp., Enterococcus spp., Escherichia spp. ve Citrobacter spp. cinslerine ait 59 suş izole edildi. En yaygın tür S. haemolyticus (\%100)' tu ve bunu E. casseliflavus (\%92.86), E. faecium ve E. coli (\%85.71), S. chromogenes (\%57.14) ve C. farmeri (\%14.29) izledi. Örneklerden fungal etken izole edilmedi. Sonuç olarak S. haemolyticus, E.casseliflavus, E. faecium ve E. coli' nin Anadolu mandası vajinal mikroflorasının bir parçası olabileceği düşünüldü.

Anahtar Kelimeler: Anadolu mandası, vajinal, bakteriyel flora, fungal flora

\section{Vaginal Bacterial and Fungal Flora in Anatolian Buffaloes}

\section{Abstract}

Vaginal microbial flora plays an important role in protecting the genital system against infections. In this study, vaginal bacterial (aerobic or facultative anaerobic) and fungal flora of Anatolian Buffaloes were investigated. Vaginal swabs were collected from 14 clinically healthy Anatolian Buffaloes who had never mated before in Dicle University Faculty of Veterinary Medicine Education Research and Training Farm. Isolation and identification of bacteria and fungi were performed using standard methods. Fifty-nine strains belonging to Staphylococcus spp., Enterococcus spp., Escherichia spp. and Citrobacter spp. genus were isolated. The most prevalent species was $S$. haemolyticus (100\%), followed by E. casseliflavus (92.86\%), E. faecium and E. coli (85.71\%), S. chromogenes (57.14\%) and C. farmeri (14.29\%). Fungal agent was not isolated from the samples. Consequently, it was thought that $S$. haemolyticus, E. casseliflavus, E. faecium and E. coli might be a part of the Anatolian Buffalo vaginal microflora.

Key Words: Anatolian Buffalo, vaginal, bacterial flora, fungal flora

\section{GiRiş}

Mandalar (Bubalus bubalis) ekolojik ve çevresel koşullara adapte olabilmeleri, kaba yemlerden yüksek oranda yararlanabilme özellikleriyle küresel ekonomide önemli bir yere sahiptir $(1,2)$. Dünya'da manda yetiştiriciliğinin büyük kısmı başta Hindistan, Pakistan ve Çin olmak üzere Asya Kıtası'nda yapılmaktadır (3). Türkiye'de Anadolu mandası yetiştiriciliği Karadeniz, İç Anadolu, Ege, Marmara ile Doğu Anadolu Bölgeleri'nin çeşitli illerinde ve Güneydoğu Anadolu'da ise Diyarbakır'da yoğunlaşmıştır $(1,4)$.

Manda yetiştiriciliğinin avantajlarının yanı sıra mandaların üretkenliği/verimliliği ruminant grubunda yer alan diğer türlere kıyasla daha düşüktür $(2,5)$. Dişi mandalarda üreme verimliliğini geç ergenlik, buzağılamanın mevsimselliği gibi faktörlerin etkilediği ve anöstrus ile döl tutmamanın (repeat breeder; RB) infertilitenin iki ana nedeni olduğunu belirtilmekte$\operatorname{dir}(2,6-8)$. RB etiyolojisi multifaktöriyeldir ve beslenme, hormonal bozukluklar, immunoinfertilite, kromozomal anomaliler, üreme sistemi anomalileri, barınak, sıcaklık, mevsim gibi çevresel etkenler, infeksiyöz etkenler ve sağlık yönetimi ile ilişkilendirilmektedir $(5,9)$.

Genital mikroflora üreme sağ|ı̆̆ı ve üreme verimliliği açısından büyük önem taşımaktadır. Vajinal mukozal ekosistem ekzojen patojenlere karşı koruma sağlayan mikroflora tarafından kolonize edilmiş epitel ve mukustan oluşmaktadır (10). Serviko vajinal mukus uterusu patojen etkenlere karşı koruyan biyolojik ve fiziksel bir bariyer oluşturmaktadır. Dinamik bir bakteri topluluğundan oluşan vajinal mikroflora da patojen mikroorganizmaların çoğalmasını ve uterusa ulaşmasını önlemeyi amaçlamaktadır (10-12). Dişi sığırlarda mikroflorayı oluşturan baskın türlerin, çalışmalar arasında farklılık göstermekle birlikte genellikle Staphylococcus, Streptococcus, Enterococcus cinslerine ve Enterobacteriaceae familyasına ait aerobik; Lactobacillus, Fusobacterium ve Peptostreptococcus cinslerine ait anaerobik bakteriyel türlerden oluştuğu bilinmektedir (10). Bakteriyel etkenlerin yanı sıra daha az 
oranda maya ve Penicillium cinsine ait fungal türlerin de vajinal mikroflorayı kolonize ettiği bildirilmiştir (12).

Mandalarda vajinal mikroflora ile ilgili az sayıda çalışma bulunmaktadır. Bununla birlikte, literatür taramasında Ülkemizde bu konuyla ilgili bir çalışmaya rastlanmamıştır. Bu çaIışmada Diyarbakır yöresindeki Anadolu mandalarının vajinal aerobik bakteriyel ve mikolojik florasının araştırılması amaçlanmıştır.

\section{MATERYAL VE METOT}

\section{Materyal}

Bu çalışmada Dicle Üniversitesi Veteriner Fakültesi Eğitim Araştırma ve Uygulama Çiftliği'nde bulunan ve yaklaşık 17 aylık, daha önce çiftleşmemiş ve klinik olarak sağlıklı 14 Anadolu mandası örneklendi. Vulva ve perineal bölge iyot-povidon solüsyonu ile dezenfekte edildikten sonra $30 \mathrm{~cm}$ uzunluğunda steril svaplar ile her bir hayvanın vajina- serviks girişinden iki sürüntü örneği alındı. Alınan örnekler soğuk zincirde Dicle Üniversitesi Veteriner Fakültesi Mikrobiyoloji Anabilim Dalı Laboratuvarı'na ulaştırıldı.

\section{Bakteriyolojik ve Mikolojik İzolasyon ve İdentifikasyon}

Bakteriyolojik izolasyon için örnekler $10 \mathrm{ml}$ steril tamponlanmış peptonlu su (Oxoid, USA) içerisine transfer edildi ve $37^{\circ} \mathrm{C}$ ' de 18 24 saat inkübe edildi. Sıvı kültürden 10'ar $\mu$ l alındı ve \%5 koyun kanlı agar (Oxoid, USA), MacConkey agar (Oxoid, USA) ve Eosin Methylen Blue agara (Oxoid, USA) pasajlanarak $37^{\circ} \mathrm{C}^{\prime}$ de $24-48$ saat aerobik koşullarda inkübe edildi (13). İnkübasyon sonrası besiyerlerindeki koloniler nutrient agarda (Oxoid, USA) saflaştırıldı ve MALDI Biotyper [(MatrixAssisted Laser Desorption/Ionization Time of Flight) Bruker Daltonics, USA)] kütle spektrometresi kullanılarak identifiye edildi.

Mikolojik izolasyon için örnekler kloramfenikol supplement $[(0.05 \mathrm{mg} / \mathrm{ml}),($ Oxoid, UK)] içeren Sabouraoud Dekstroz agara (Oxoid, UK) gömülerek ekildi ve $27^{\circ} \mathrm{C}^{\prime}$ de 21 gün süreyle inkübe edildi (13).

\section{BULGULAR}

Alınan örneklerin tamamından (\%100) iki ile altı farklı bakteri türü izole edildi. Örneklerin \%42.86 (6/14)'dan beş, \%28.57 (4/14)'den dört, \%21.43 (3/14)'ten üç ve \%7.14 (1/14)'ten altı farklı bakteri türü izole edildi. Gram pozitif bakteriler, örneklerin tamamında (\%100) tespit edilirken; iki örnekte (\%14.29) Gram negatif bakterilere rastlanmadı. İolatların \%77.05 (47/61)'ini Gram pozitif, \%22.95 (14/61)'ini ise Gram negatif bakteriler oluşturdu. Örneklerin \%100'ünden (14/14) Staphylococcus haemolyticus (S. haemolyticus) izole edildi ve bunu \%92.86 (13/14) ile Enterococcus casseliflavus (E.casseliflavus), \%85.71 (12/14) ile Enterococcus faecium (E. faecium) ve Escherichia coli (E. coli), \%57.14 (8/14) ile Staphylococcus chromogenes (S. chromogenes) ve \%14.29 (2/14) ile Citrobacter farmeri (C. farmeri) izledi. Örneklerin hiçbirinden fungal etken izole edilmedi.

\section{TARTIŞMA VE SONUÇ}

Dişi genital sistemi infekte eden bakteriyel etkenler sadece uterus ve yumurtalığın işlevini değil aynı zamanda hipotalamus ve hipofizdeki yüksek kontrol merkezlerini de etkileyerek reprodüktif bozukluklara sebep olabilmektedir (14). Mikroorganizmaların genital kanala girişi vajina yoluyla olduğundan vajinal mikroflora uteral infeksiyonların önlenmesinde önemli bir rol oynamaktadır $(10,12)$. Bu sebeple bu çalışmada sağlıklı Anadolu mandalarının vajinal aerobik bakteriyel ve mikolojik florası araştırıldı.

Çalışmada sağlıklı manda vajinal örneklerinin tamamından S. haemolyticus ve örneklerin \%57.14'ünden S. chromogenes'in izole edilmesi bazı araştırmacıların Staphylococcus spp. ve Staphylococcus cinsine ait farklı türlerin mandaların vajinal florasının bir parçası olduğunu bildiren bulgularını destekler niteliktedir (15-18). Bununla birlikte Patel ve ark. (2009) postpartum dönemde sağlıksız görünen vajinal akıntılardan izole ettikleri bakterilerin \%37.03'ünün Staphylococcus spp. olduğunu bildirmişlerdir (19). Bu açıdan vajinal floranın bir parçası olan bakterilerin östrus siklusunda, doğum sırasında ya da sonrasında uterusa ulaşarak, dişi mandalarda en önemli hastalıklardan biri olan postpartum metritise sebep olabileceği de göz önünde bulundurulmalıdır $(8,11)$.

Enterococcus cinsine ait E.casseliflavus (\%92.86) ve $E$. faecium (\%85.71), S. haemolyticus'tan sonra vajinal floradan izole edilen en yaygın türler olarak belirlendi. E. faecalis'i ElJakee ve ark. (2008) farklı reprodüktif aşamalardaki mandalarda (prepuberta, östrus, anöstrus, gebelik, postpartum) \%12.50-39.39 aralığında (20) ve Ahmed ve ark. (2007) östrustaki mandalarda \%39.39 olarak rapor etmişlerdir (17). Otero ve ark. (1999) Enterococcus cinsinin Nelore Hereford düvelerinin vajinal florasının baskın popülasyonlardan biri olduğunu bildirmişlerdir (21). Ancak bazı çalışmalarda vajinal örneklerden yapılan izolasyonlarda Enterococcus spp. ile ilgili bir veriye rastlanmamıştır $(15,16,18,22)$. Srinivasan ve ark. (2021) canlı ve dinamik bir ekosisteme sahip vajinal floradaki baskın türlerin değişkenlik gösterebildiğini ve çalışmalar arasında farklılıklar olabileceğini bildirmişlerdir (10).

Örneklerin \%85.71'inden izole edilen $E$. coli de en yaygın türlerden biri olarak tespit edildi. Bu bulgu E. coli' nin manda vajinal florasında en yaygın türlerden biri olduğunu bildiren çalışmaları destekler niteliktedir $(15-17,20,22)$. Ancak Patel ve ark. (2009) postpartum dönemde sağlıksız görünen vajinal akıntılardan izole ettikleri bakterilerin \%18.51'inin E. coli olduğunu bildirmişlerdir (19). Yukarıda bahsedildiği gibi normal floranın parçası olan bakterilerin farklı sebeplerle uterusa ulaşarak dişi mandalarda metritise sebep olabileceği unutulmamalıdır.

C. farmeri vajinal örneklerin \%14.29'undan izole edildi. Bazı çalışmalarda vajinal örneklerden yapılan izolasyonlarda Citrobacter spp. ile ilgili bir veriye rastlanmamakla birlikte $(15,16,18,20,22)$ El-Jakee ve ark. (2008) Citrobacter cinsine ait Citrobacter diversus (C. diversus)' un inceledikleri farklı reprodüktif aşamalardaki (prepuberta, östrus, anöstrus, gebelik, postpartum) mandaların vajinal örneklerinde \%7.535.71 aralığında olduğunu (20), Ahmed ve ark. (2007) östrustaki mandalarda \%25.75 olduğunu bildirmişlerdir (17). Raza ve ark. (2013) ise Nili-Ravi mandalarının uteral florasını incelemiş ve Citrobacter spp. prevalansının tüm örneklerde \%10 olduğunu, bunun $\% 80$ 'inin abort yapmış ve $\% 10$ 'unun gebe olmayan hayvanlarda tespit edildiğini bildirmiştir. Ayrıca Citrobacter spp. ile gebelik oranları arasında istatistiksel olarak 
anlamlı bir ilişki olduğunu ve Citrobacter cinsinin Nili-Ravi mandalarının üreme sistemi ile ilgili problemlerle bağlantılı olabileceğini bildirmiştir (23). Çalışmamızdaki Citrobacter spp. izolasyonu yukarıda bahsedilen bazı araştırma bulgularıyla benzerlik göstermekle birlikte Raza ve ark. (2013)' nın araştırma bulgularının da göz önünde bulundurulmasının Anadolu mandalarının üreme sağlığı açısından faydalı olabileceği düşünüldü.

İncelenen örneklerde herhangi bir fungal etken tespit edilmedi. Verma ve ark. (1999) reprodüktif bozukluğu olan mandaların \%18.6'sından, ineklerin ise \%21.89'undan fungal etken izole etmişler ve bu izolatların RB, endometritis ve servisit ya da vajinitli hayvanlara ait olduğunu bildirmişlerdir (24). Dişi sığır genital kanalında mikolojik flora ile ilgili çalışmalar incelendiğinde ise fungal etkenlerin izolasyon oranları arasında farklılıklar olduğu görülmektedir. Panangala ve ark. (1978) normal fertil gruptaki ineklerin \%8.3'ünden Candida ve Candida benzeri mantar ile \%8.3'ünden filamentöz etkenlerin izole edildiğini (25), Ross (2003) da vajiniti olmayan ineklerin \%46'sından fungal etken tespit edildiğini bildirmişlerdir (26). Çalışmamızda fungal etken tespit edilmemiş olmasının örnek sayımızın azlığı ile ilgili olabileceği gibi hayvanların bulunduğu ekosistemle de ilişkili olabileceği düşünüldü.

Sonuç olarak bu çalışmada Anadolu mandası vajinal mikroflorasında S. haemolyticus, E.casseliflavus, E. faecium ile $E$. coli' nin en baskın türler olduğu ve herhangi bir fungal etkenin izole edilmediği belirlendi. Mikroflora kompleks bir yapıya sahiptir ve bu kompleks yapının anlaşılabilmesi için 16S rRNA sekanslama uygulamaları ile mikrobiyota çeşitliliğinin ortaya çıkarılması oldukça önemlidir. Bu çalışmanın, Anadolu mandalarının vajinal mikroflorası ile ilgili bir fikir oluşturmasının yanı sıra örnek sayısının artırılarak metagenomik yöntemlerle incelenmesinin yararlı olabileceği düşünüldü.

\section{TEŞEKKÜR}

Bu çalışmanın gerçekleşmesinde izolasyon ve identifikasyon aşamasındaki katkılarından dolayı Doç. Dr. Simten YEŞiLMEN $A L P^{\prime}$ a teşekkürlerimizi sunarız.

\section{ÇIKAR ÇATIŞMASI}

Yazarlar çıkar çatışması olmadığını beyan ederler.

\section{KAYNAKLAR}

1. Yilmaz O, Ertugrul M, Wilson RT. (2012). Domestic Livestock Resources of Turkey. Trop Anm Health Pro. 44(4): 707-714.

2. Warriach HM, McGill DM, Bush RD, Wynn PC, Chohan FR. (2015). A Review of recent Developments in Buffalo Reproduction. Asian Australas J Anim Sci. 28: 451-455.

3. FAO (2014) FAOSTAT Database. Food and Agriculture Organization of the United Nations, Rome, Italy. Erişim: http://www.fao.org/3/ai3590e.pdf. Erisim tarihi: 01 Temmuz 2021.

4. Sariozkan S. (2011). Türkiye' de Manda Yetiştiriciliğinin Önemi. Kafkas Univ Vet Fak Derg. 17(1): 163-166.

5. Purohit GN. (2008). Recent Development of in the Diagnosis and Therapy of Repeat Breeding Cows and Buffaloes. CAB Rev Perspect Agricul Vet Sci Nutr Natur Res. 3(62): 1-33.

6. Barile VL. (2005). Improving Reproductive Efficiency in Female Buffaloes. Livest Prod Sci. 92: 183-194.
7. Perera BM. (2008). Reproduction in Domestic Buffalo. Reprod Domest Anim. 43: 200-206.

8. Saraswat CS, Purohit GN. (2016). Repeat Breeding: Incidence, Risk Factors and Diagnosis in Buffaloes. Asian Pac J Reprod. 5(2): 87-95.

9. Ali A, Abdel-Razek AK, Derar R, Abdel-Rheem HA, Shehata SH. (2009). Forms of Reproductive Disorders in Cattle and Buffaloes in Middle Egypt. Reprod Domest Anim. 44(4): 580-586.

10. Srinivasan M, Adnane M, Archunan G. (2021). Significance of Cervico-Vaginal Microbes in Bovine Reproduction and Pheromone Production-A Hypothetical Review. Res Vet Sci. 135: 66-71.

11. Azawi OI. (2010). Uterine Infection in Buffalo Cows: A Review. Buffalo Bull. 29(3): 54-171.

12. Appiah MO, Wang J, Lu W. (2020). Microflora in the Reproductive Tract of Cattle: A Review. Agriculture. 10(6): 232.

13. Markey B, Leonard F, Archambault M, Cullinane A, Maguire D. (2013). Section 3: Mycology. In: Clinical Veterinary Microbiology. Edwards R, Hewat C (editors). 2th. ed. Missouri, USA: Mosby Elsevier; 2013. pp. 457-521.

14. Sheldon IM, Dobson H. (2004). Postpartum Uterine Health in Cattle. Anim Reprod Sci. 82: 295-306.

15. Kumar S, Sharma U, Malik MA, Kumar S. (2019). Vaginal Bacterial Profile in Buffaloes Following Treatment with Progesterone Insert. J Anim Res. 9(2): 359-361.

16. Wakayo BU, Brar PS, Prabhakar S et al. (2016). Impact of Vaginal-microflora at Artificial Insemination on Pregnancy Outcomes in Murrah Buffalo. Indian Vet. J. 93(03): 76-78.

17. Ahmed WM, El-Jakee JA, El-Seedy FR, El-Ekhnawy KI, Abd ElMoez SI. (2007). Vaginal Bacterial Profile of Buffalo-Cows in Relation to Ovarian Activity. Glob Vet. 1(1): 01-08.

18. Oba E, de Amorim Ramos A, Langoni H, Paes AC, Bicudo SD. (1992). Microbial flora in the Vagina of Buffalo Cows During Reproductive and Productive Activity. Semin Cienc Agrar. 13(1): 18-21.

19. Patel PP, Panchal MT, Kalyani IH, Kavani FS. (2009). Antibiotic Sensitivity Spectrum of Bacterial Isolates from Cervico Vaginal Mucus of Postpartum Rural Buffaloes. Intas Polivet. 10(1): 29-31.

20. El-Jakee, JA, Ahmed WM, El-Seedy FR, Abd El-Moez SI. (2008). Bacterial profile of the genital tract in female buffaloes during different reproductive stages. Glob Vet. 2(1): 7-14.

21. Otero C, De Ruiz CS, Ibañez R, Wilde OR, de Ruiz Holgado AAP, Nader-Macias ME. (1999). Lactobacilli and Enterococci İsolated from the Bovine Vagina During the Estrous Cycle. Anaerobe. 3(5): 305-307.

22. Singh BR, Singh RK, Singh V. (2014). Carriage of multiple drugresistant bacteria in vagina of apparently healthy swamp buffaloes in Nagaland. Adv Anim Vet Sci. 2(5): 292-295.

23. Raza S, Rabbani M, Ahmad N, et al. (2013). Uterine Microbial Flora of Nili-Ravi Buffalo During Estrus and its Relationship with Pregnancy Rate in Pakistan. Buffalo Bulletin. 32(special issue 2): 564-567.

24. Verma S, Katoch RC, Jand SK, Sharma BM, Nigam P. (1999). Mycobiotic Flora of Female Genitalia of Buffaloes and Cows with Reproductive Disorders. Vet Res Commun. 23(6): 337-342.

25. Panangala VS, Fish NA, Barnum DA. (1978). Microflora of the Cervico-Vaginal Mucus of Repeat Breeder Cows. Can Vet J. 19(4): 83.

26. Ross HJ. 2003. Bacterial and Fungal Organisms in the Vagina of Normal Cows and Cows with Vaginitis. Master Thesis. Texas A\&M University. pp:12-16.

Sorumlu Yazar:

Nurdan KARACAN SEVER

Dicle Üniversitesi Veteriner Fakültesi, Mikrobiyoloji

Anabilim Dalı, Diyarbakır, TÜRKIYE

E-posta: nurdankaracan@hotmail.com 